\title{
The Application of Leader Following Method and Cubic Polynomial Path Planning Algorithm with Formation Control on Multi-Robot Systems
}

\author{
Nuri Efe Tatl1 ${ }^{1 *}$,Dilara Fidan ${ }^{2}$, Beyzanur Kalayc1 ${ }^{3}$, Cem Çeber $^{4}$, Pınar Oğuz Ekim ${ }^{5}$ \\ ${ }^{1}$ İzmir University of Economics, Faculty of Eng., Department of Mechatronics Eng., İzmir, Turkey, (ORCID: 0000-0003-3975-1605), nuriefetatli@gmail.com \\ ${ }^{2}$ İzmir University of Economics, Faculty of Eng., Department of Mechatronics Eng., İzmir, Turkey, (ORCID: 0000-0002-3408-3735), dilaraafidan@gmail.com \\ ${ }^{3}$ İzmir University of Economics, Faculty of Eng., Department of Mechatronics Eng., İzmir, Turkey, (ORCID: 0000-0002-8949-5569), beyzanur.kalayci@outlook.com \\ ${ }^{4}$ İzmir University of Economics, Faculty of Eng., Department of Mechatronics Eng., İzmir, Turkey, (ORCID: 0000-0003-2355-3196), cebercem@gmail.com \\ ${ }^{5}$ İzmir University of Economics, Faculty of Eng., Dep. of Electrical and Electronics Eng., İzmir, Turkey, (ORCID: 0000-0003-1860-4526), pinar.ekim@ieu.edu.tr
}

(First received 1 October 2021 and in final form 30 December 2021)

(DOI: $10.31590 /$ josat.1003330)

ATIF/REFERENCE: Tatlı, N. E., Fidan, D., Kalayc1, B., Çeber, C. \& Oğuz-Ekim, P. (2021). The Application of Leader Following Method and Cubic Polynomial Path Planning Algorithm with Formation Control on Multi-Robot Systems. European Journal of Science and Technology, (31), 921-927.

\begin{abstract}
In this study, the movement of mobile robots on a certain path by preserving their formation and with a leader-follower was examined. Knowing the initial and final positions and orientations of the leader robot, the cubic polynomial was used and the positions of the leader at all points on the path were found. Then, the positions, where the followers were found with the homogeneous transformations, were calculated in order to provide the equilateral triangle formation. The velocity profile of the leader was calculated with certain calculations by determining the maximum velocity for the leader. Controller has been designed for the leader's right and left motors. In order to find the velocity of the follower robots, it was calculated by using the position information that the robots should be at a certain moment. The resulting graphics showed how the robots would create a path at certain angles. The distance values that should be between the robots and the location information from the UWB (Ultra-wideband) were shown on the Matlab graphics. The calculated linear velocities and desired velocities of the leader and follower robots are shown graphically. In the control diagram created for the left and right motors of the leader robot, it has been shown how the linear and angular velocities are affected by PID.
\end{abstract}

Keywords: path planning, formation control, leader-following method, UWB (Ultra-wideband), cubic polynomial, mobile robots, multi-robot systems, homogeneous transformation.

\section{Lider Takip Metodu ve Kübik Polinom Yol Planlama Algoritmasının Formasyon Kontrollü Çoklu Robot Sistemlerinde Uygulanması}

Öz

Bu çalışmada, mobil robotların oluşumlarını koruyarak ve lider takip ederek belirli bir yol üzerinde hareketi incelenmiştir. Lider robotun başlangıç ve son konumları ve yönelimleri bilinerek kübik polinom kullanılmış ve yol üzerindeki tüm noktalarda liderin konumları bulunmuştur. Daha sonra eşkenar üçgen oluşumunu sağlamak için homojen dönüşümler ile takipçilerin bulunduğu konumlar hesaplanmıştır. Lider için maksimum hız belirlenerek belirli hesaplamalar ile liderin hız profili hesaplanmıştır. Kontrolör, liderin sağ ve sol motorları için tasarlanmıştır. Takip eden robotların hızlarını bulmak için robotların belirli bir anda olması gereken konum bilgileri kullanılarak hesaplanmıştır. Ortaya çıkan grafikler, robotların belirli açılarda nasıl bir yol oluşturacağını göstermiştir. Robotlar arasında olması gereken mesafe değerleri ile UWB'den (Ultra geniş bant) gelen konum bilgisi Matlab grafiği üzerinde gösterilmiştir. Lider ve takipçi robotların hesaplanan lineer hızları ve istenilen hızları grafiksel olarak gösterilmiştir. Lider robotun sol ve sağ motorları için oluşturulan kontrol diyagramında lineer ve açısal hızların PID'den nasıl etkilendiği gösterilmiştir.

Anahtar Kelimeler: yol planlama, oluşum kontrolü, lider izleme yöntemi, kübik polinom, mobil robotlar, çok robotlu sistemler, homojen dönüşüm.

* Corresponding Author: pinar.ekim@ieu.edu.tr 


\section{Introduction}

Industrial robots began to join the workforce a few decades back. Through the years, this automation advancement has begun to dominate the workforce. Coupled with its cost-effectiveness, the robots are also starting to cost less than their human equivalents. This helps understand their growth in prominence in the industrial environments. Instead of a big and costly robot, it is desired to have multiple small and cost-effective mobile robots to fullfill the desired tasks such as carrying heavy loads. Hence the formation control of multiple robots is needed. In other words, the swarm robotics is an approach that aims to perform the task of the same type of robots with simple abilities rather than performing the task by robots with superior abilities (Misir, O. et al ,2020).

In (A. Gautam et al., 2012), the most widely used formation control approaches were discussed and compared in terms of some properties. The leader-follower approach's working principle was explained as "Uses several agents as leaders and others as followers. This method is easy to understand, and it ensures formation maintenance if the leaders are disturbed. However, the desired formation cannot be maintained if followers are perturbed unless formation feedback is implemented." in (K.D. Do et al., 2012).

There are different approaches in the leader-follower method too. In (X. Zhang et al., 2020) the distributed control for leaderfollowing formation of mobile robots with unknown amplitudes of leader's velocity was considered. In (Kiliçarslan Ouach, M. et al., 2021), the leader-Follower formation control, the control rule aimed to preserve the distance and angle of the first follower relative to the leader, and the distance values of the second follower relative to the leader and to the first follower. In (Z. Qiao et al., 2020), they proposed to take the communication condition into account, build and dynamically update a graph for group partition. In (Yaşar, E. et al.,2020) in order to the main mission robot to create a path most appropriate to the target point, this path was created with the communication of the swarm robot individuals and the main mission robot. In (A. Loria et al., 2016) the formation control problem on straight-line paths with timevarying nonlinear controllers which rely on a property of persistence of excitation for nonlinear systems was solved. There are also different categorization approaches such as positionbased control, displacement-based control and distance-based control and they were discussed in detail in (Oh K et al., 2015). To control a group of robots in terms of communication networks, there are also control types such as centralized and decentralized (K.D. Do et al., 2012), (H. Rezaae et al., 2014).

There are different ways to build a multi-agent system using a leader-follower approach. The whole system can be seen as one body and one leader directs the whole system. Besides, there can be multiple leader-follower sets. The follower robot can also be a leader of another robot. In (Jinyan et al., 2005), the tree graph theory was used to formalize more complex general configurations ( $\mathrm{N}$ robots) based on the formations of two-robot systems. In ( $\mathrm{Li}$ et al., 2005), the cartesian coordinate representation was used instead of the polar coordinate representation to eliminate the possible singularity points that may occur as the denominator in the controller formula may be zero at certain points.

Most of the formation control algorithms use position and velocity measurements to achieve the desired formation and pose. In (X. Liang et al., 2018), Liang $\mathrm{G}$ et al. proposed a new leaderfollower formation tracking control schemes without using both position and velocity measurements by using onboard perspective cameras.

There is also a method that uses only position measurements and estimates the leader's velocity. In (H.A. Poonawala et al., 2013) Poonawala et al. presented a method that guarantees convergence of the relative position of any follower robot (concerning its leader) to desired values and their controllers do not require sensing of the leader's velocity. They used an adaptive method to estimate the leader's forward velocity. The drawback of (H.A. Poonawala et al., 2013) is that the condition for the controller is that the leader robot moves with a constant velocity.

In the real world, there are always obstacles that are dynamic or static. It is important to have a reliable obstacle avoidance algorithm that keeps the formation while avoiding the obstacles. In (Jinyan et al., 2005), the existence of the virtual shell surroundings for each robot is assumed. The work in (H. Xiao et al., 2016) contains two models: 1) separation-bearing-orientation scheme (SBOS) for regular formation control and 2) separationdistance scheme (SDS) for obstacle avoidance. In (M. Sisto et al., 2006), the fuzzy logic formation controller and fuzzy intercollision avoidance controller were developed for the model. In (H. Jiao et al.,2016), to solve the low recognition efficiency during dynamic changes in the positioning of the tags the ALOHA anti-collision algorithm was combined with the tag capacity issues in the Ultra-Wideband (UWB) indoor location. In the literature (Yıldırım, M. et al.,2021) made a conclusion on the path planning of multiple robots by observing linear and nonlinear objective functions.

In this study, the leader-follower method is proposed to achieve the right triangular form using three agents and the algorithm uses the leader robot's estimated velocity. The path planning for the leader robot was developed using the cubic polynomial method. A calculated path is used to calculate the control inputs of the leader robot. The estimated velocity of the leader robot is used to control the follower robots. The most important point of this project is that the mobile robot plans the most appropriate path according to the conditions and acts in accordance with that plan.

\section{Material and Method}

\subsection{The Path Planning}

Based on the leader's first position and orientation $\left(\mathrm{X}_{1}, \mathrm{Y}_{1}, \theta_{1}\right)$ and the leader's final position and orientation $\left(\mathrm{X}_{2}, \mathrm{Y}_{2}, \theta_{2}\right)$, the values on the path are found thanks to the cubic polynomial equation of $3^{\text {rd }}$ order in (1).

$$
y=a_{3} * x^{3}+a_{2} * x^{2}+a_{1} * x+a_{0}
$$

For the initial and final conditions, the values are implemented to the cubic polynomial equation and the matrix in (2) was provided.

$$
\left[\begin{array}{cccc}
1 & x_{1} & x_{1}{ }^{2} & x_{1}{ }^{3} \\
1 & x_{2} & x_{2}{ }^{2} & x_{2}{ }^{3} \\
0 & 1 & 2 x_{1} & 3 x_{1}{ }^{2} \\
0 & 1 & 2 x_{2} & 3 x_{2}{ }^{2}
\end{array}\right] *\left[\begin{array}{l}
a_{0} \\
a_{1} \\
a_{2} \\
a_{3}
\end{array}\right]=\left[\begin{array}{c}
y_{1} \\
y_{2} \\
\tan \theta_{1} \\
\tan \theta_{2}
\end{array}\right],
$$

From this matrix equation $\mathrm{a}_{0}, \mathrm{a}_{1}, \mathrm{a}_{2}$, $\mathrm{a}_{3}$ values were obtained. 


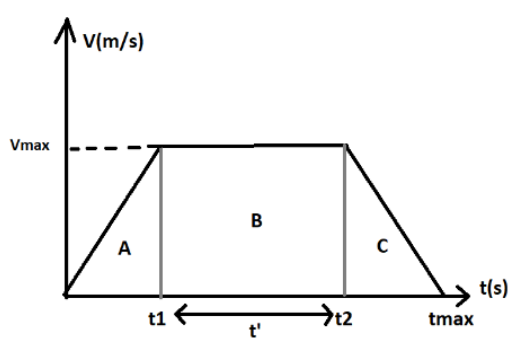

Fig.1. Trapezoidal velocity profile with $\mathrm{V}_{\max }$ and time information.

While creating the velocity profile, predetermined maximum speed $\left(\mathrm{V}_{\max }\right)$ and maximum acceleration $\left(\mathrm{a}_{\max }\right)$ values should be found. Thanks to these values, the parameters such as acceleration time (3), the path taken by the robot (4) and, the acceleration area (5) are calculated. The speed profile was selected as the trapezoidal velocity profile in this work. A, B and $\mathrm{C}$ represent the area they are in.

$$
\begin{aligned}
& t_{1}=\frac{V_{\max }}{a_{\max }}, \\
& S_{\max }=\int_{x_{1}}^{x_{2}} \sqrt{1+y^{\prime 2}} d x=A+B+C \\
& A=0.5 * V_{\max } * t_{1}
\end{aligned}
$$

The time information when the velocity is constant (6) and the maximum time the robot reach (7) is obtained from the equations respectively:

$$
\begin{aligned}
& t^{\prime}=t_{2}+t_{1}=\frac{S_{\max }-2 * A}{V_{\max }} \\
& t_{\max }=2 * t_{1}+t^{\prime} \\
& S_{2}=S_{\max }-A
\end{aligned}
$$

Using the above equations, the time function is written as:

$$
T(S)=\left\{\begin{array}{lc}
\sqrt{\frac{2 * S}{a_{\max }}} & S \leq A \\
\frac{S-A}{V_{\max }}+t_{1} & A<S \leq S_{2}, \\
t_{\max }-\sqrt{\frac{2 *\left(S_{\max }-S\right)}{a_{\max }}} & S_{2}<S
\end{array}\right.
$$

Thanks to the calculations, the position (x, y) of the leading robot and the time when it is in that position are known.

\subsection{The Localization with UWB}

$\mathrm{X}$ and $\mathrm{Y}$ values obtained by the path planning on MATLAB were used as source data. Anchors are used to finding the position of the robot in the environment. These anchors can be placed randomly in the room, but their location information must be known. Each anchor is considered with (x, y, z) values. With this information, the UWB based algorithm was used to determine the instant positions of the robots (P. Oğuz-Ekim et. al., 2019). By knowing the positions, the desired position and the speed of the follower robots will be determined.

\subsection{The Velocity Calculations of The Leader}

Since the velocity profile is trapezoidal as shown in Figure 1, the velocity calculation has 3 parts:

$$
V(t)=\left\{\begin{array}{c}
a_{\max } * t, t \leq t_{1} \\
V_{\max } t_{1}<t \leq t_{2} \\
V_{\max }-a_{\max } *\left(t-t_{2}\right), t>t_{2}
\end{array},\right.
$$

To calculate the angular velocity, the radius of curvature (11) is calculated for every $\mathrm{x}$ value.

$$
R(x)=\frac{\sqrt{\left(1+(y u(x))^{2}\right)^{3}}}{|y u(x)|},
$$

Using V and R, the angular velocity (w) at each step calculated;

$$
\mathrm{W}=\mathrm{V} / \mathrm{R},
$$

The left and right wheel velocities (13) and (14) for differential drive are calculated using the angular velocity (w), the radius of curvature (R), and distance between the wheels (1);

$$
\begin{aligned}
& V_{\text {left }}=w *\left(R-\frac{l}{2}\right), \\
& V_{\text {right }}=w *\left(R+\frac{l}{2}\right),
\end{aligned}
$$

\subsection{Control Diagram for Leader}

The controller is designed to control the left and right wheel motors of the leader robot. The controller takes left and right linear velocities as an input. Since the simulation environment gives perfect results, the transfer functions of the motors were designed a little differently to consider some error.

PID values were determined considering the following information. Proportional $(\mathrm{P})$ value was added to speed up the system, that is, to reduce the rise time, and then the Derivative (D) value was added to reduce the value of the resulting damping. Integral (I) value was not preferred much to avoid delay in the system, but (I) is added to the parts to reduce the error.

\subsection{Homogeneous Transformation}

In this paper, the positions of the follower robots at the back should be found by taking the position of the leader as a reference. While the leader robot changes its position, it also changes the angle it looks at in other words its orientation, in motion. Therefore, the homogeneous transformation equation (15) was used to find the correct locations. The calculation was made between the coordinate plane of the leader robot and the general coordinate system.

$$
P^{\text {global }}=O_{\text {leader }}^{\text {global }}+R_{\text {leader }}^{\text {global }} * P^{\text {leader }} .
$$

The vectors for the homogeneous transformations are given in Figure 2. The required values are the instantaneous position of the leader, the instantaneous angle of the leader with the global, and 
the $x-y$ positions from the leader to the follower. Since the rotation is performed around the $\mathrm{z}$-axis, the rotation matrix on the $\mathrm{z}$-axis is used.

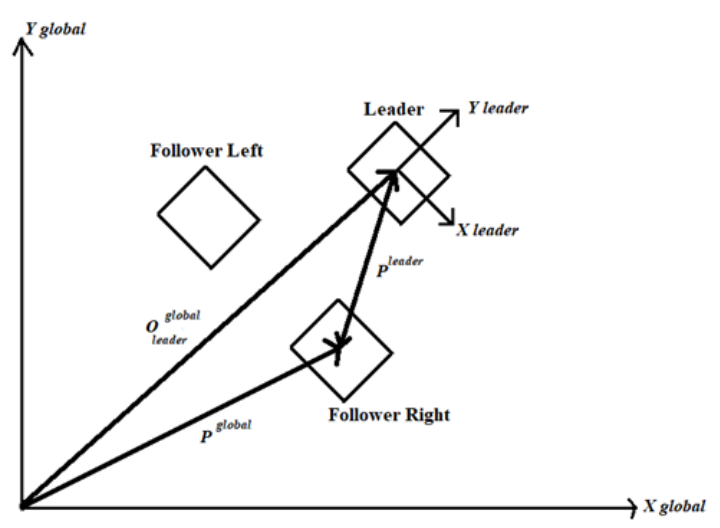

Fig.2. Vectors for homogeneous transformations

Here $\theta$ (16) is the orientation of the leader according to the global coordinate system. It is calculated as;

$$
\begin{aligned}
& \theta(t)=\operatorname{atan}\left(\frac{Y(t)-Y(t-1)}{X(t)-X(t-1)}\right), \\
& R_{\text {leader }}^{\text {global }}=\left[\begin{array}{ccc}
\cos \theta & -\sin \theta & 0 \\
\sin \theta & \cos \theta & 0 \\
0 & 0 & 1
\end{array}\right] .
\end{aligned}
$$

If it is desired to find the positions of the followers according to the leader, the formation in which the robot is located should be considered. The robot is thought to provide the equilateral triangle formation as shown in Figure 3. When the side length is considered as $\mathrm{d}$, the following equations emerge. The rotation matrix is represented as (17).

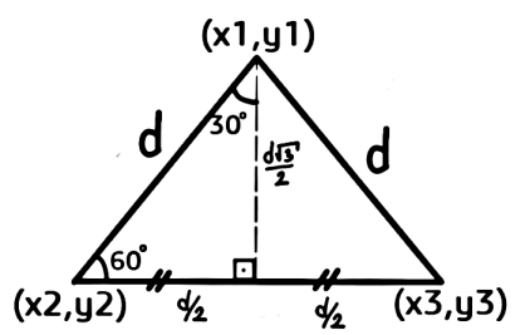

Fig.3. Followers' coordinate calculations according to the leader.

The position vector of the left-follower (18) according to leader:

$$
P_{\text {left }}^{\text {leader }}=\left[\begin{array}{c}
-\frac{d}{2} \\
-\frac{d \sqrt{3}}{2} \\
0
\end{array}\right],
$$

The general formula for the left-follower (19):

$$
P_{\text {left }}^{\text {global }}=\left[\begin{array}{c}
\text { leader_x} \\
\text { leader_y } \\
0
\end{array}\right]+R_{\text {leader }}^{\text {global } * P_{\text {left }}^{\text {leader }},}
$$

The position vector of the right-follower according to the leader (20):

$$
P_{\text {right }}^{\text {leader }}=\left[\begin{array}{c}
\frac{d}{2} \\
-\frac{d \sqrt{3}}{2} \\
0
\end{array}\right],
$$

The general formula for the right-follower (21):

$$
P_{\text {right }}^{\text {global }}=\left[\begin{array}{c}
\text { leader_x } \\
\text { leader_y } y \\
0
\end{array}\right]+R_{\text {leader }}^{\text {global }} * P_{\text {right }}^{\text {leader }} .
$$

In this way, by using both translation and rotation, the positions of the followers known in the coordinates of the leader are calculated according to the global frame.

\subsection{The Velocity Calculations of Followers}

The arc length of the curvature between each step (L) and the corresponding radius of curvature $(\mathrm{R})$ is calculated using MATLAB functions by Are Mjaavatten (Are et al., 2021).

$$
\begin{gathered}
V_{\text {follower }}(t)=\frac{L(t)-L(t-1)}{t-(t-1)}, \\
w_{\text {follower }}=\frac{V_{\text {follower }}}{R_{\text {follower }}}, \\
V_{\text {follower-left }}=w_{\text {follower }} *\left(R_{\text {follower }}-\frac{l}{2}\right), \\
V_{\text {follower-right }}=w_{\text {follower }} *\left(R_{\text {follower }}+\frac{l}{2}\right) .
\end{gathered}
$$

The flowchart of the algorithm is given in Figure 4.

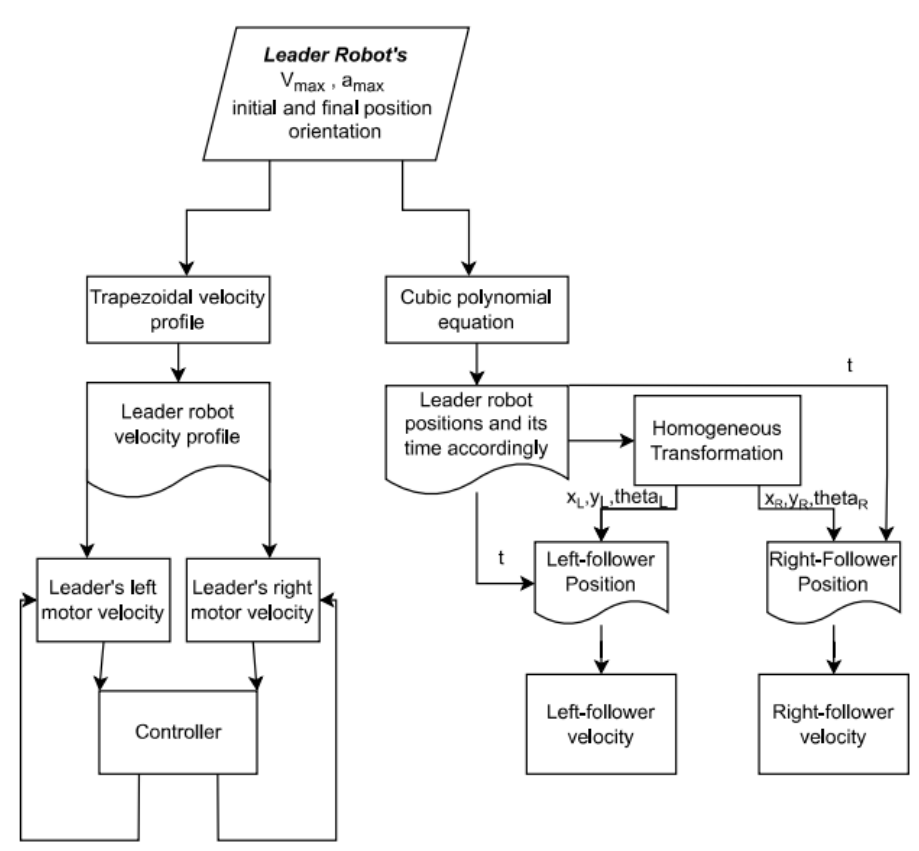

Fig.4. Flowchart of the algorithm 


\section{Results and Discussion}

\subsection{The Path Generation}

The algorithm uses the tangent function to calculate the coefficients. Since the tangent uses inputs between -90 degrees to 90 degrees (first and fourth quadrants of the cartesian coordinate system), the algorithm does not work properly on the second and third quadrants. The paths of the leader and the follower robots can be observed in Figure 5 and it can be concluded that during the whole trajectory the triangular formation of robots is preserved.

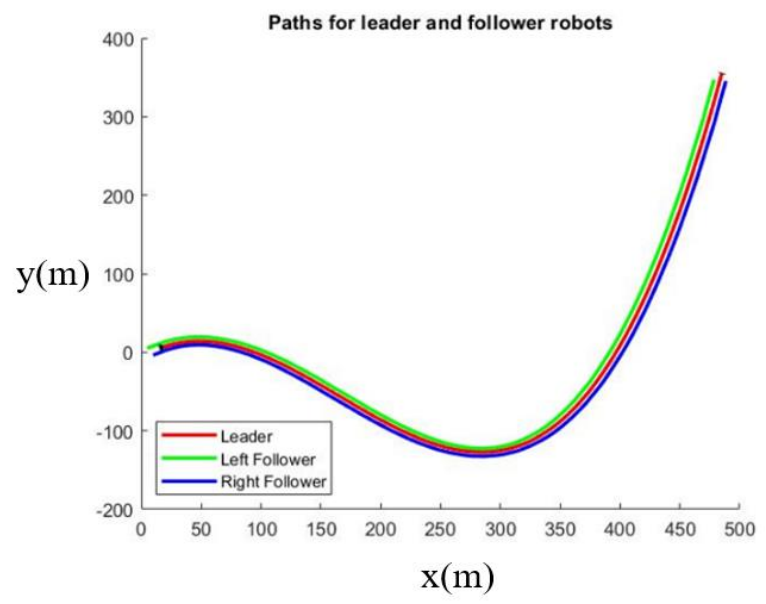

Fig.5. Theta values in first quadrant $\left(\theta_{1}=30^{\circ}, \theta_{2}=80^{\circ}\right)$

For the initial and final orientations in the first and fourth quadrants, the algorithm works fine, and the formation is preserved.

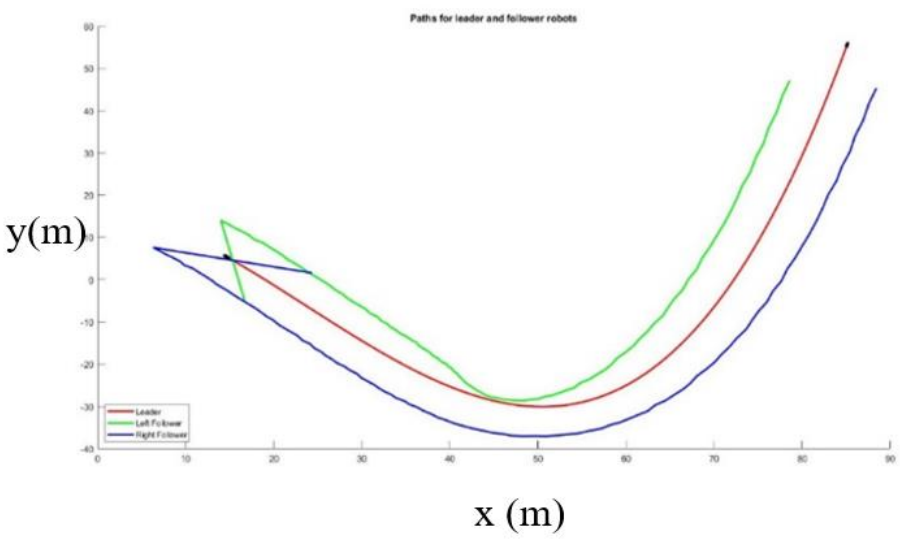

Fig.6. Paths for robots $\left(\theta_{1}=130^{\circ}, \theta_{2}=80^{\circ}\right)$

Since arctangent is used to calculate the angle (16) in the algorithm, it gives an error for the angles in the second and third quadrants, this is observed in Fig.6. The angles in this area are perceived as being subtracted from 180 degrees and are processed accordingly. This is one of the results encountered.

\subsection{UWB Localization}

The errors on the position of the leader that is calculated via UWB are negligible which are shown in Figure 7. Since the desired positions for the followers are calculated using the leader's position on UWB, the followers have errors in their positions. For the right triangular formation, the desired distance between robots should be 10 meters. Figure 8 shows that the distances between the leader and the followers have bigger errors than the distance between followers.

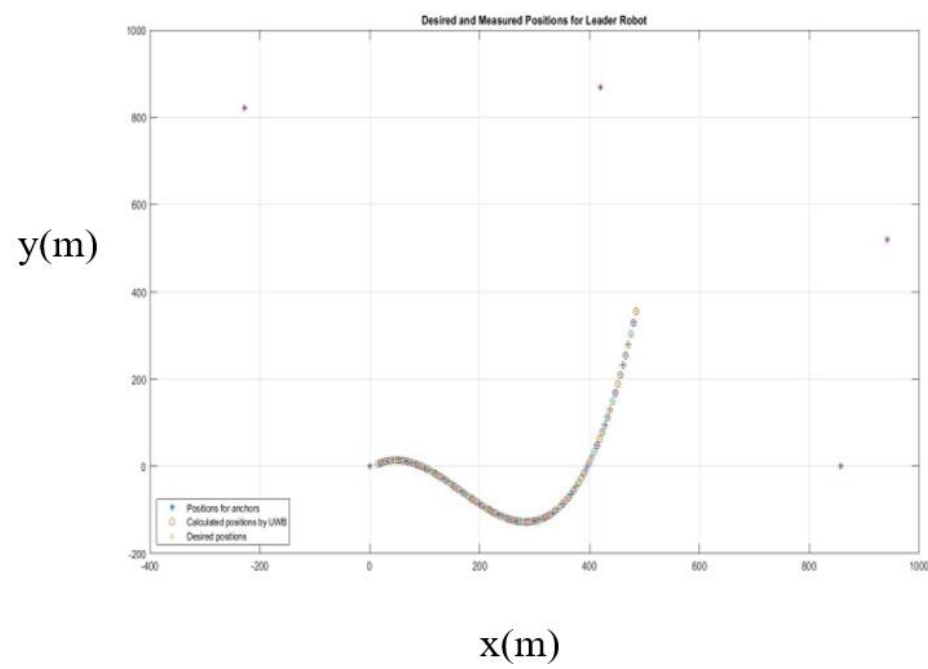

Fig.7. The Desired and calculated positions for the leader robot. The errors are not too big; thus, they are negligible.

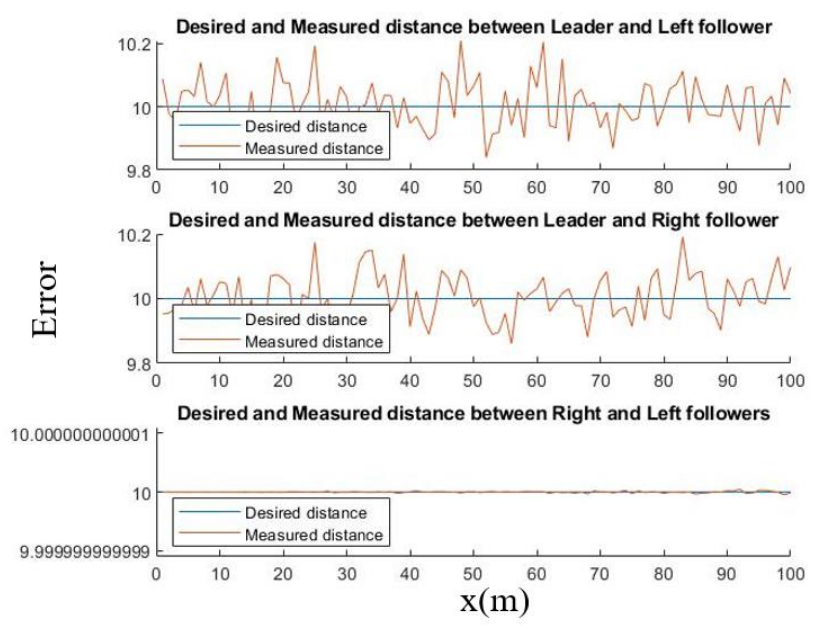

Fig.8. Errors on formation via the desired distance between robots

\subsection{Velocity}

As shown in Figure 9, firstly the robots turn right and then they turn left. So, in the first part, the robot that is located on the left of the leader should take more distance and for turning left, the robot that is located on the right of the leader should take more distance. Although the results have some noise, it can be easily seen that the velocity profiles match their paths. 


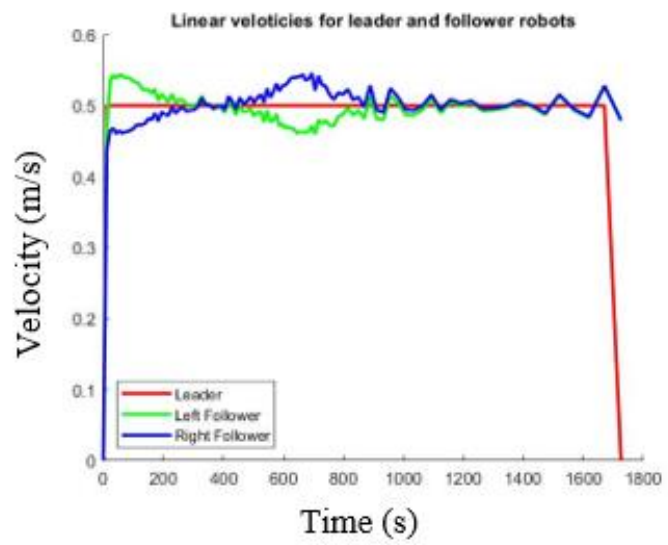

Fig.9. Velocity profiles of robots

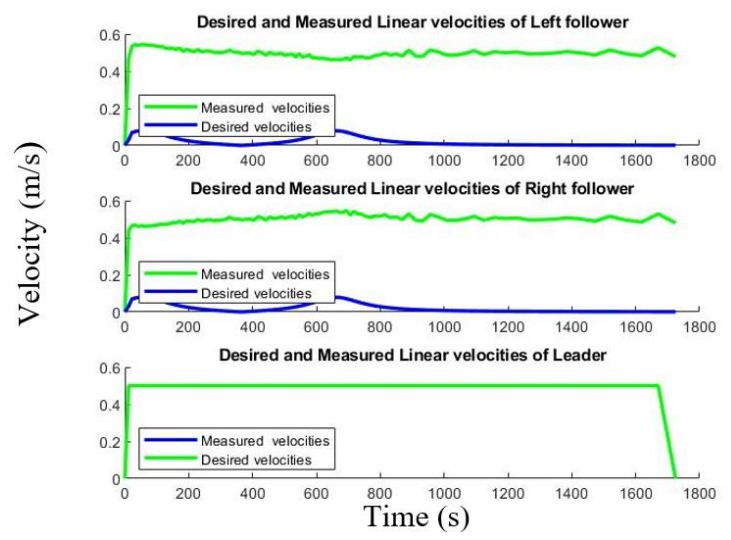

Fig.10. Desired and calculated velocity profiles

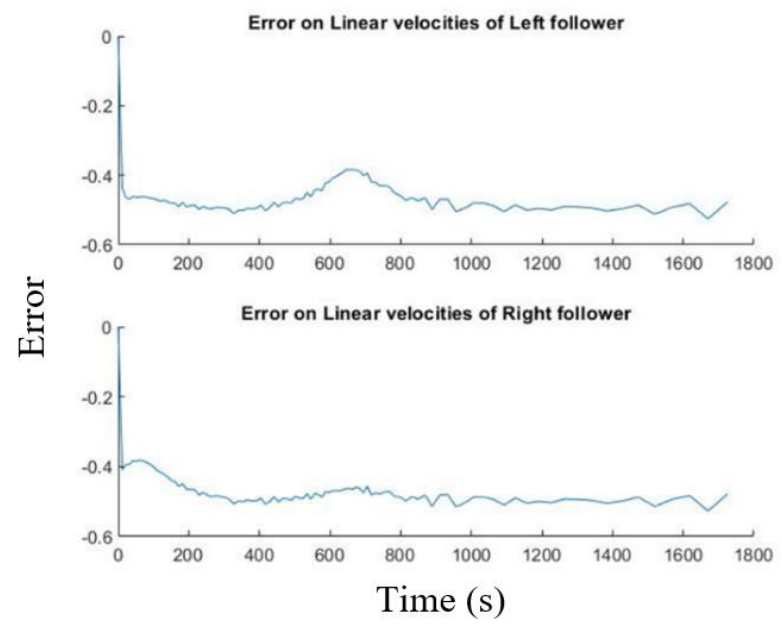

Fig.11. Errors on Linear velocities for follower robots

The noise is cumulatively increasing according to calculations as shown in Figure 10. In Figure 11, the maximum error is nearly 0.2 on a distance basis; however, on a velocity basis, the error is nearly 2.5 times greater than the error on a distance basis.

\subsection{Controller}

The linear and the angular velocities were examined with and without the PID controller. In the linear velocity case shown in Figure 12, the system was stable and had a rapid response time; however, it had oscillations and could not reach the desired velocity. In the angular velocity case shown in Figure 13, the system again had a rapid response time, but it was unstable and had oscillations.

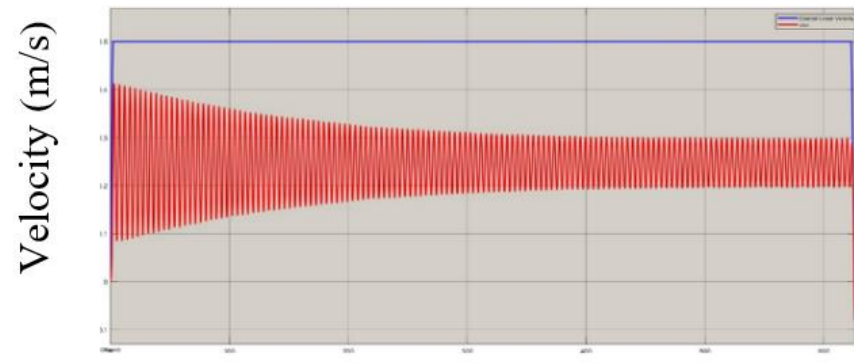

Time (s)

Fig.12 Linear Velocity without PID controller

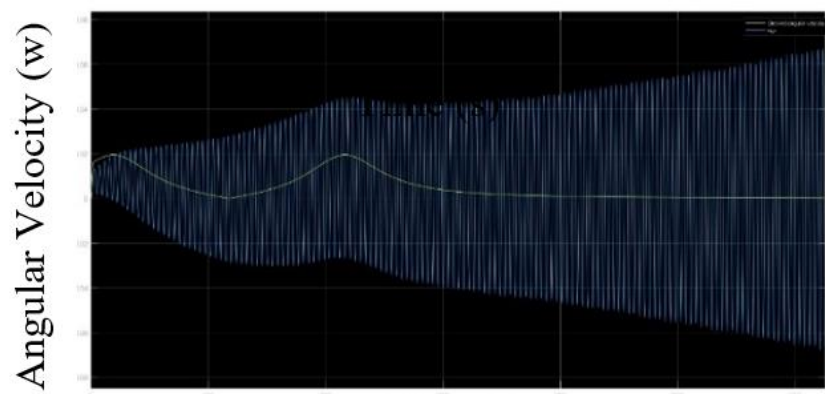

Time (s)

Fig.13 Angular Velocity without PID controller

After the PID controllers were tuned, both systems became stable. The error on linear velocity was measured as $0.03 \mathrm{~m} / \mathrm{s}$ and the error on angular velocity was measured as 0.01 degree/sec.

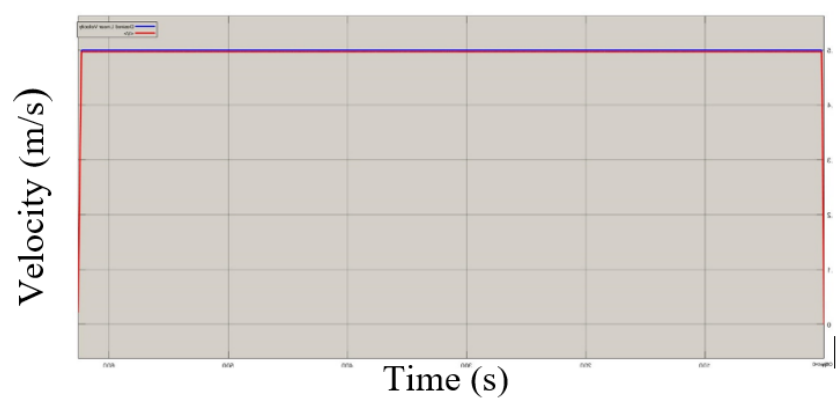

Fig.14 Linear Velocity with PID controller

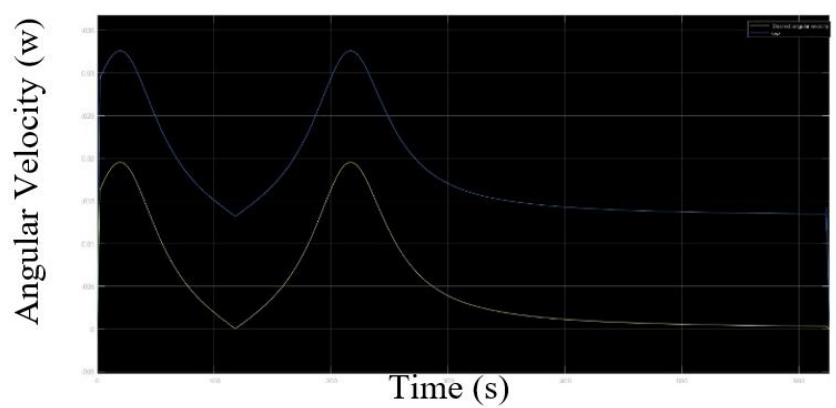

Fig.15 Angular Velocity with PID controller

\section{Conclusions and Recommendations}

The speed control and formation algorithm of autonomous robots in a certain formation were examined. In the path planning, if the first and last points of the robot and the orientations are known, the path through which the robot passes is reached with a 3 -degree cubic polynomial, but due to the $\tan \theta$ equality in the 
matrix used in the solution, the angles are always given between -90 and +90 values. To solve this problem and to get more accurate data, a pure-pursuit algorithm will be used.

The speed information of the leader has been reached thanks to the time piecewise function obtained from the path taken by the leader robot. Thus, the position, speed and orientation of the leader robot with respect to time were calculated. By combining this information and the homogeneous transformation method, the positions of the follower robots were calculated. The velocity calculations were made with this information for the follower robots that needed to be found at certain points at a certain time.

\section{Acknowledge}

This research is supported by Scientific and Technological Research Council of Turkey (TUBITAK), project number $119 \mathrm{E} 376$.

\section{References}

A. Gautam and S. Mohan, "A review of research in multi-robot systems," 2012 IEEE 7th International Conference on Industrial and Information Systems (ICIIS), Chennai, 2012, pp. 1

A. Loria, J. Dasdemir and N. Alvarez Jarquin, "Leader-Follower Formation and Tracking Control of Mobile Robots Along Straight Paths," in IEEE Transactions on Control Systems Technology, vol. 24, no. 2, pp. 727-732, March 2016, doi: 10.1109/TCST.2015.2437328.

Are Mjaavatten (2021). Curvature of a 1D curve in a 2D or 3D space, MATLAB Central File Exchange Retrieved July 10, 2021.

E. Yaşar (2020). Using Swarm Robots in Motion Planning. European Journal of Science and Technology, (20),24-29.

H. A. Poonawala, A. C. Satici and M. W. Spong, "Leaderfollower formation control of nonholonomic wheeled mobile robots using only position measurements," 2013 9th Asian Control Conference (ASCC), Istanbul, 2013, pp. 1-6, doi: 10.1109/ASCC.2013.6606313.

H. Jiao, C. Shen, G. Feng and P. Ling, "Research on multi-tag anti-collision algorithm based on UWB real-time positioning system," 2016 IEEE Conference on Wireless Sensors (ICWiSE), Langkawi, 2016, pp. 54-58, doi: 10.1109/ICWISE.2016.8188542.

H. Rezaee and F. Abdollahi, "A Decentralized Cooperative Control Scheme With Obstacle Avoidance for a Team of Mobile Robots," in IEEE Transactions on Industrial Electronics, vol. 61, no. 1, pp. 347-354, Jan. 2014, doi: 10.1109/TIE.2013.2245612.

H. Xiao, Z. Li and C. L. Philip Chen, "Formation Control of Leader-Follower Mobile Robots' Systems Using Model Predictive Control Based on Neural-Dynamic Optimization," in IEEE Transactions on Industrial Electronics, vol. 63, no. 9, pp. 5752-5762, Sept. 2016, doi: 10.1109/TIE.2016.2542788.

Jinyan Shao, Guangming Xie, Junzhi $\mathrm{Yu}$ and Long Wang, "Leader-Following Formation Control of Multiple Mobile e-ISSN: 2148-2683
Robots," Proceedings of the 2005 IEEE International Symposium on, Mediterranean Conference on Control and Automation Intelligent Control, 2005., Limassol, 2005, pp. 808-813, doi: 10.1109/.2005.1467118.

K.D. Do, Formation control of multiple elliptical agents with limited sensing ranges, Automatica, Volume 48, Issue 7, 2012, Pages 1330-1338, ISSN 0005-1098

Li, Xiaohai \& Xiao, Jizhong. (2005). Robot Formation Control in Leader-Follower Motion Using Direct Lyapunov Method. 10.

M. Kılıçarslan Ouach \& T. Eren (2021). Mobil Robotların Formasyon Kontrolünde Giriş Kısıtlamaları. International Journal of Engineering Research and Development, 13 (2), 680-689. DOI: 10.29137/umagd.908696

M. Sisto and D. Gu, "A Fuzzy Leader-Follower Approach to Formation Control of Multiple Mobile Robots," 2006 IEEE/RSJ International Conference on Intelligent Robots and Systems, Beijing, 2006, pp. 2515-2520, doi: 10.1109/IROS.2006.281698.

M. Y. Y1ldırım, R. Akay (2021). Investigation of Linearity in Path Planning of Mobile Robot. European Journal of Science and Technology, (24), 138-142.

P. Oğuz-Ekim, S. Tekkök, B. Bostanci, E. Söyünmez and F. Yeaganli, "The lidar and uwb based source localization and initialization algorithms for autonomous robotic systems", 11th International Conference on Electrical and Electronics Engineering (ELECO), November 2019.

O. Misır\& L. Gökrem (2020). Flexible and Scalable Aggregation Behavior Method for Swarm Robots. European Journal of Science and Technology, (Special Issue), 100-109.

Oh K K, Park M C, Ahn H S. A survey of multi-agent formation control[M]. Pergamon Press, Inc. 2015

W. Guanghua, L. Deyi, G. Wenyan, J. Peng, "Study on Formation Control of Multi-Robot Systems", Third International Conference on Intelligent System Design and Engineering Applications, 2013

X. Liang, H. Wang, Y. Liu, W. Chen and T. Liu, "Formation Control of Nonholonomic Mobile Robots Without Position and Velocity Measurements," in IEEE Transactions on Robotics, vol. 34, no. 2, pp. 434-446, April 2018, doi: 10.1109/TRO.2017.2776304.

X. Zhang, X. Yu, J. Lu and W. Lan, "Distributed Leaderfollowing Formation Control for Mobile Robots with Unknown Amplitudes of Leader's Velocity," 2020 39th Chinese Control Conference (CCC), Shenyang, China, 2020, pp. 4889-4894, doi: 10.23919/CCC50068.2020.9188817.

Z. Qiao, J. Zhang, X. Qu and J. Xiong, "Dynamic Self-Organizing Leader-Follower Control in a Swarm Mobile Robots System Under Limited Communication," in IEEE 2020 Access, vol. 8, pp. 53850-53856, 2020, doi: 10.1109/ACCESS.2020.2980778. 